\title{
Cardiovascular risk in carotid disease: assessment of doppler sonography and biomarker results
}

\author{
Risco cardiovascular e doença carotídea: \\ avaliação de resultados de doppler e biomarcadores
}

Rogério Jorge Barbosa de Oliveira; Ana Paula Caires dos Santos²; Lázaro Silveira Santos Junior³; Marcos Soares Vieira ${ }^{4}$; Roque Aras Junior ${ }^{5}$; Fábio David Couto ${ }^{6}$ : Ricardo David Couto ${ }^{7}$

\begin{abstract}
Introduction: Atherosclerosis and correlated cardiovascular problems, whose mechanical and physiological disorders cause thickening and hardening of blood vessels, are among the main causes of death worldwide. Objective: To assess plasma concentrations of biomarkers from the lipid metabolism and carotid doppler sonography results by correlating them with atherogenic carotid disease. Methods: the study comprised 66 patients aged $57.5 \pm 15.5$ years (20-77), from which $63 \%$ were female. Serum markers and doppler sonography images were used to evaluate the association with atherogenic carotid disease (ACD). Results: There was a higher prevalence of ACD among females (33\% vs. 15\%), age range 56-65, showing a relative risk (RR) of 1.56 among females $(p<0.002$; Fisher, Katz). Concerning high density lipoprotein cholesterol (HDL-C) and carotid stenosis classification, North American Symptomatic Carotid Endarterectomy Trial (NASCET), 76\% of patients showed HDL-C within the protection range, from which 31 individuals presented level I (normal). $81 \%$ of them showed HDL-C $>40 \mathrm{mg} / \mathrm{dl}$ and $19 \%$ had HDL-C $\geq$ $40 \mathrm{mg} / \mathrm{dl}$. The prevalence of HDL-C $>40 \mathrm{mg} / \mathrm{dl}$ at levels II, III and IV was considerable. There was no difference in HDL-C among the groups $(\phi=0.4910$; unpaired $t$ test). Furthermore, there was no difference in paraoxonase (PON1) activity when stratified to HDL-C $>$ and $<40 \mathrm{mg} / \mathrm{dl}$ $(p>0.05)$. Conclusion: The female group displayed higher ACD prevalence at 56-65 age range, with RR of 1.56 times higher. These findings substantiate the importance of analyzing this group and age range carefully, inasmuch as the absence of hormonal protection may increase ACD risk and ultimately influence HDL antioxidant activity due to its direct action on PON1. Triglycerides (TG)/HDL-C ratio indicates cardiovascular risk and impaired reverse cholesterol transport.
\end{abstract}

Key words: atherosclerosis; echocardiography vascular; paraoxonase; lipoproteins.

\section{INTRODUCTION}

Cardiovascular problems, from which atherosclerosis complications are worth noting, are among the main causes of death worldwide. It is characterized by impaired mechanical and physiological conditions that cause thickening and hardening of coronary, cerebral and peripheral vessels, leading to chronic inflammation and presence of foam cells in the vascular walls ${ }^{(6)}$. Dyslipidemias considerably influence the formation of atheroma plaques in vessel walls, mainly due to its interference in the structure and function of high density lipoprotein (HDL) ${ }^{(15)}$. HDL is responsible for the removal of exceeding cholesterol from extra-hepatic tissues, transporting it again to the liver to be excreted. This process is called reverse cholesterol transport ${ }^{(15)}$.

First submission on $02 / 02 / 12$; last submission on $24 / 03 / 12$; accepted for publication on 31/03/12; published on 20/02/13

1. Master of Science in Health Biotechnology and Investigative Medicine at Fundação Oswaldo Cruz-Bahia (FIOCRUZ-BA); cardiologist; lieutenant commander of Hospital Naval de Salvador, Brazilian Navy.

2. Currently a Master's candidate in Pharmacy (Clinical Diagnosis) at Faculdade de Farmácia da Universidade Federal da Bahia (UFBA); biochemist at Maternidade Climério de Oliveira.

3. Graduate in Clinical Analysis and Public Health; biochemist at the Clinical Laboratory of UFBA College of Pharmacy.

4. Currently a Master's candidate in Health Biotechnology and Investigative Medicine at FIOCRUZ-BA; biochemist; lieutenant commander of Hospital Naval de Salvador, Brazilian Navy.

5. Doctor in Health and Medicine by UFBA Medical School; associated professor at UFBA Medical School; cardiologist; medical director of Ana Neri Hospital - UFBA.

6. Doctor in Human Pathology by FIOCRUZ-BA; adjunct professor of Biomolecular Biology and Genetics at Centro de Ciências Agrárias, Ambientais e Biológicas da Universidade Federal do Recôncavo da Bahia (CCAAB-UFRB).

7. Post doctorate in Health and Biotechnology and Investigative Medicine by FIOCRUZ-BA; doctor in Clinical Chemistry by Universidade de São Paulo (USP); laboratory coordinator of UFBA hospitals. 
It is commonly asserted that atherogenesis is linked with the presence of oxidized (modified) low density lipoprotein (LDL) in vascular walls ${ }^{(28)}$. LDL oxidation by free radicals present in the intima region of vessels induces the migration of monocytes and other inflammatory cells to the endothelium, tunica intima and media ${ }^{(10,15)}$. Atherosclerosis involvement in several sites cause resemblance between carotid atherosclerosis and coronary atherosclerosis risk factors ${ }^{(8)}$. The carotid intima-media thickness (IMT) is an early vascular alteration originated from the endothelium dysfunction and corresponds to the initial stage of atherosclerosis ${ }^{(7)}$.

Currently, intima-media thickness is regarded as an important measurement to indentify atherosclerosis, inasmuch as it shows the correlation of risk factors with other vascular atherosclerotic diseases ${ }^{(17)}$. Several lipoprotein markers are notably associated with IMT such as the increase in triglycerides (TG) concentrations, non-HDL cholesterol (non HDL-C) and apolipoprotein (apo) $\mathrm{B}^{(17)}$. However, some investigations have demonstrated that the cause-effect relation between plasma biomarkers and cardiovascular risk requires further elucidation, mainly considering the conflicting data published in this area ${ }^{(12)}$.

Hence, this study aims to asses the relation between carotid atherosclerosis and metabolic lipoprotein alterations through imagery tests (doppler sonography), laboratory evaluation of paraoxonase activity (PON1) and calculated indexes from lipidic profile determinations.

\section{OBJECTIVE}

To verify the possible interrelation between plasma concentrations of lipid metabolism biomarkers and PON1 activity with carotid doppler sonography results by correlating them with atherogenic carotid disease (ACD).

\section{METHODOLOGY}

\section{Study outline and sample}

A prospective study was carried out by means of cooperation between Hospital Naval de Salvador and the Faculdade de Farmácia da Universidade Federal da Bahia (UFBA). It comprised the military population and their dependants, regardless of gender, race or religion. The sample was selected for convenience, including a total of 66 individuals aged between 20 and 77 from 171 participants initially registered for the research protocol at Hospital Naval de Salvador. All participants signed a free informed and clarified consent prior to taking part in the study.

\section{- Inclusion criteria}

Both genders; age group: young and elderly adults (20 to 77); non-hospitalized outpatients from Hospital Naval de Salvador; signed informed consent; carotid doppler sonography after lipidic profile assessment; lipidic profiles independent from normal reference values, even in patients with diabetes mellitus (DM), arterial hypertension (AH), hypothyroidism or dyslipidemia, undergoing treatment or not.

\section{- Exclusion criteria}

Hospitalized patients; presence of acute pathologies; no consent to take part in the research; individuals with renal failure (serum creatinine $>2 \mathrm{mg} / \mathrm{dl}$ ) and/or nephritic syndrome (proteinuria $>3 \mathrm{~g} / \mathrm{l}$ and serum albumin $<3 \mathrm{~g} / \mathrm{l})$; those who had not undergone vascular doppler sonography; clinical evidence of any chronic disease such as hepatopathy, conjunctive tissue diseases and neoplasias; terminal diseases.

\section{Diagnostic imaging}

The exams were carried out at the Center of Vascular Ultrasonography and Bioimaging from the Naval Hospital. They were all performed by the same examiner with Envisor C serie M2540A, PHILLIPS Medical Systems, uni-bidimensional mode with color doppler in order to evaluate and perform the clinical and ultrasonographic analysis of plaques and carotid atherosclerotic irregularities.

\section{Classification of stenotic lesions}

In accordance with the North American Symptomatic Carotid Endarterectomy Trial (NASCET), the stenotic levels caused by atheroma plaques in carotid arteries were sorted into the following levels: level I (normal), level II (between 1\% and 29\%), level III (between 30\% and 49\%), level IV (between 50\% and 69\%), level V (between $70 \%$ and $99 \%$ ) and level VI or occlusion $\left(100 \%{ }^{(27)}\right.$.

\section{LABORATORY DETERMINATIONS}

\section{Clinical laboratory}

After a twelve-hour fasting period, serum samples of approximately $10 \mathrm{ml}$ were collected and sent to the Clinical Biochemistry Laboratory in order to determine the concentrations of total cholesterol (TC), its fractions and TG. HDL-C was determined by homogeneous method (Labtest, Brazil). Concentrations of very low density lipoprotein cholesterol (VLDL-C) and low density lipoprotein cholesterol (LDL-C) were calculated according to Friedwald equation $(1972)^{(9)}$ or according to the homogeneous method to assess LDL-C when TG was higher than $150 \mathrm{mg} / \mathrm{dl}$. All analyses were conducted by automated Labmax 240, Labtest, Brazil. Sample aliquots were applied to assess lipidic profile markers and PON1 activity. Furthermore, Gazzinano and Castelli indexes I and II were calculated.

\section{RESEARCH LABORATORY}

\section{Low density lipoprotein (LDL) particle size assessment (LDL)}

After determining serum TG and HDL cholesterol concentration, LDL particle size was assessed according to Maruyama et al. equation ${ }^{(19)}$, which is obtained by TG/HDL-C ratio (Gazziano index) ${ }^{(31)}$. 


\section{PON1 activity}

PON1 activity was assessed according to the method described by Mackness et al..$^{(16)}$. $140 \mu \mathrm{l}$ of Tris-HCl $0.1 \mathrm{M}, \mathrm{pH} 8.05$ containing $2 \mathrm{mmol} / \mathrm{l}$ of calcium chloride (CaCl2) and $1.1 \mathrm{mmol} / \mathrm{l}$ of paraoxon (Sigma Chemical Co.) was added to $7 \mu \mathrm{l}$ serum. The sample was distributed into 96 deep-well plates in duplicates. The reading was performed at $405 \mathrm{~nm}$ wavelength and $37^{\circ} \mathrm{C}$ by Microplate Reader, Benchmark, BIO-RAD. Six readings were done at one-minute intervals in order to calculate PON1 activity. The result was achieved by multiplying the mean absorbance variation by factor.

Factor $=$ total reaction volume $(\mathrm{TRV})(\mathrm{ml}) / \varepsilon 405 \times$ sample value (SV) $(\mathrm{ml}) \times$ cuvette thickness $(\mathrm{cm})$, in which $\varepsilon 405$ $1805 \mathrm{ml}^{(-1)} \mathrm{cm}^{(-1)}$. Therefore, PON1 activity $=$ factor $\times \Delta$ abs $/$ minute.

\section{Statistical analysis}

The descriptive analysis was conducted after the assessment of centrality and dispersion in order to obtain summary measures, which was followed by Kolmogorov-Smirnov normality test. Grubbs test was carried out to detect outliers at the beginning of inferential statistical analysis. Subsequently, parametrical and/or non parametrical tests were conducted according to data distribution in relation to the mean number. The differences with critical level $p<0.05(5 \%)$ at confidence interval (CI) of $95 \%$ were considered significant for all data. Software GraphPad Instat v.3.05 was applied for data analysis.

\section{Ethical aspects}

This investigation was approved by the Ethics Committee of Maternidade Climério de Oliveira/UFBA. In accordance with the National Health Council regulation 196/1996, all patients were admitted after the free informed consent.

\section{RESULTS}

Concerning distribution and age range, there was a higher prevalence of participants above the age of 66. Nonetheless, it was observed that the presence of atherosclerotic disease generally occurs in the male group from $36-45$ years (Figure) whereas in the female group, the disease was detected from 46-55 years, becoming increasingly higher in both groups with the aging process. None of the groups had the disease within the age range 20-35.

The participants' clinical profile evaluation showed prevalence in 35 patients (53\%) with ACD; 54 (82\%) were on regular medication to treat previous diseases (systemic arterial hypertension $[\mathrm{SAH}]$, DM, cerebrovascular accident [CVA], dyslipidemia, hypothyroidism or coronary disease); 45 (68\%) were hypertensive; 48 (73\%) had dyslipidemia, from which 25 (53\%) had associated carotid arterial disease; seven were coronary patients; three (4\%) showed CVA; 42 $(64 \%)$ were on regular use of hypolipidemic drugs.

The prevalence of carotid stenosis levels was calculated according to NASCET classification $(1991)^{(5)}$. It was confirmed that $47 \%$ of patients had level 1 (normal - without atherosclerotic plaques) whereas levels II, III and IV totaled 53\% of the cases. In accordance with Barnet $e t a l{ }^{(3)}$, mild stenosis $(<50 \%$ obstruction of vascular

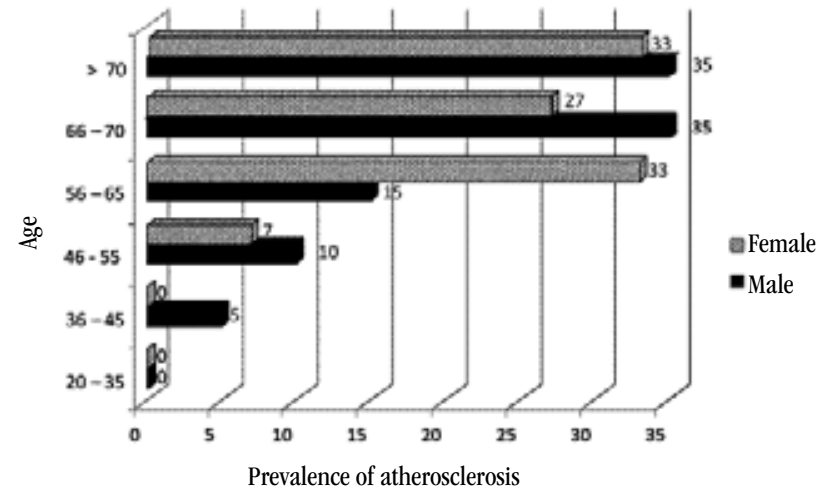

FIGURE - Presence of carotid atherosclerosis according to age range and gender. ACD was more prevalent in the female group (33\% vs. 15\%) in comparison with the male group (5665 years of age), with RR 1.56 for women ( $<<0.002$; Fisher's test with Katz approximation). $A C D$ : atherogenic carotid disease; RR: relative risk.

lumen) was predominant, hence levels II and III totaled $44 \%$ of the cases. There were no patients from levels $\mathrm{V}$ and $\mathrm{VI}$ (occlusion) in the present study.

The performance of Fisher's exact test between carotid stenosis levels (NASCET) and the concentration of HDL-C ( $>$ ou $\leq 40 \mathrm{mg} / \mathrm{dl}$ ) did not prove any significant association.

As to HDL-C concentration and carotid stenosis classification (NASCET), 50 (76\%) from the total of 66 patients presented HDL-C levels within the protection zone. 25 (81\%) from the total of 31 individuals classified as level I showed serum HDL-C $>40 \mathrm{mg} / \mathrm{dl}$ and six patients (19\%) showed HDL-C $\leq 40 \mathrm{mg} / \mathrm{dl}$. There was prevalence of serum HDL-C $>40 \mathrm{mg} / \mathrm{dl}$ in levels II, III and IV. There was no considerable difference in HDL-C concentrations within the groups ( $\phi$ $=0.4910$, unpaired $\mathrm{t}$ test). Table 1 shows the centrality and dispersion measurements, calculated Castelli I, II and Gazziano indexes for groups ACD and non ACD.

There was no significant difference in PON1 activity when stratified to HDL-C $>$ and $<40 \mathrm{mg} / \mathrm{dl}$ (Table 2).

\section{DISCUSSION}

For convenience, the patients selected for this study were from a general outpatient clinic for on and off duty military personnel and their dependants. The distribution of participants according to their age range showed higher prevalence among those above 65 years. As expected, the attendance of younger patients proved to be less frequent due to behavioral patterns, regardless of the fact that the population was made of militaries or civilians ${ }^{(21)}$. The sample revealed the presence of $\mathrm{ACD}$ in the male group as from 36-45 years of age, although it may be observed in the second decade of life ${ }^{(28)}$. on the other hand, in the female group the disease was detected as from 46 years of age, becoming higher in both groups as individuals aged. None of the groups presented ACD within the age range (2035 years) at the present study. Pertaining to carotid atherosclerosis, Framingham's study demonstrated a prevalence of stenosis $\geq 50 \%$ 
TABLE 1 - Gazziano, Castelli I and II indexes and calculated centrality and dispersion measures

\begin{tabular}{ccccc}
\hline Índice & $n$ & Mean & SD & $p^{*}$ \\
Castelli I & & & 1.4 & 0.992 \\
Normal & 34 & 3.4 & 1 & \\
ACD & 32 & 3.4 & 1.2 & 0.303 \\
Castelli II & & & 0.7 & \\
Normal & 34 & 1.9 & 1.7 & 1.814 \\
ACD & 32 & & 0.406 \\
Gazziano & 31 & 2.7 & 2.806 \\
Normal & 35 & 2.9 & \\
ACD & & & \\
\hline
\end{tabular}

* Student's t distribution with different standard deviation

SD: standard deviation; $A C D$ : atherogenic carotid disease.

TABLE 2 - Estimated PON1 activity data for HDL-C $>$ and $\leq 40 \mathrm{mg} / \mathrm{dl}$

\begin{tabular}{cccccc}
\hline Parameters & Mean & 50 th & SD & $n$ & $p^{*}$ \\
$*$ PON1, HDL-C & 108.6505 & 115.4600 & 46.05 & 29 & 0.1704 \\
$>40 \mathrm{mg} / \mathrm{dl}$ & & & & \\
$*$ PON1, HDL-C & 93.9108 & 98.1450 & 32.84 & 08 \\
$<40 \mathrm{mg} / \mathrm{dl}$ & & & & \\
\hline
\end{tabular}

PON1: paraoxonase; HDL-C: high density lipoprotein cholesterol; SD: standard deviation.

among the population above 65 years of age (7\% for females and $9 \%$ for males) ${ }^{(23)}$. At the present study, the general prevalence for stenosis levels II, III and IV was 53\%, classified as mild stenosis, from which 47\% were level I, 44\% were levels II and III and 9\% were level IV, namely mild and moderate stenosis of vascular lumen. ACD was more prevalent in the male group $(36-45 ; 46-55 ; 66-70$ and above 70 years of age). However, this was not evinced in the age range of 56 to 65 , in which there was a prevalence of $33 \%$ in the female group opposed to $15 \%$ in the male group, RR 1.56 to females in this age range $(p<$ 0.002; Fisher's test with Katz approximation) (Figure).

Transversely, the transition to menopause has been associated with subclinical disease levels, which are assessed by carotid intima-media thickness and arterial distensibility ${ }^{(30)}$. Furthermore, during this subclinical phase, serum LDL-C concentration increases, whereas HDL-C concentration decreases ${ }^{(20)}$.

These changes in the lipidic profile may be estimated by the use of ratios and markers of inflammatory processes such as high sensibility $\mathrm{C}$ reactive protein (hsCRP) and the $\mathrm{TG} / \mathrm{HDL}-\mathrm{C}$ ratio ${ }^{(31)}$. Comparing data within the same group, the progression of IMT was noticed. According to Wildman et al. ${ }^{(32)}$, these data may also attest the expected menopause effect with higher progression of subclinical disease among women who are in transition for perimenopause or postmenopause. The yielded results for both perimenopause and postmenopause corroborate the Atherosclerosis Risk in Communities (ARIC) study, in which the average annual progression of IMT was 0.0086 millimeters among women and 0.0091 millimeters among men (age range: 45-64). In the present investigation, the mean IMT was $0.083 \pm$
0.029. Accordingly, the menopause transition maybe related to the accelerated progression of subclinical atherosclerosis and may be diagnosed through the direct effects caused by the hormonal, lipidic profile and vascular changes. The difference between genders has been documented in population studies, in which the incidence of a first CVA due to large-vessel atherosclerosis is four times higher among men ${ }^{(4)}$. According to Kapral et al. ${ }^{(13)}$, the frequency of carotid endarterectomy is lower among women in comparison with men, though it is not well established if this difference is related to triage type, disease prevalence or other factors. It has been noticed that women are submitted to carotid imaging less frequently than men (6,389 female patients, $48 \%$, $p<0.0001)$ and they also present less carotid stenosis $(7.4 \%$ versus $11.5 \%, p<0.0001)$. Kapral et al. ${ }^{(13)}$ study did not evidence any difference for the subgroup severe stenosis (odds ratio $0.75 ; 95 \%$ CI 0.49 to 1.15 ). Additionally, levels $\mathrm{V}$ and VI (NASCET criteria) were not observed in the study. As to clinical profile, our present approach, 54 patients were in use of regular medication to previous diseases (SAH, dyslipidemia, DM, CVA, hypothyroidism or coronary diseases), 42 were in use of hypolipidemic medication (simvastatin) and 35 presented ACD. According to Park et al. ${ }^{(22)}$, modifiable predictors such as $\mathrm{AH}$, smoking and DM are well established risk factors for ACD in several investigations. In Framingham's study, independent risk factors such as age, smoking, systolic arterial pressure, dyslipidemia and significant alcohol consumption among men were also connected with carotid atherosclerosis ${ }^{(2)}$. In some studies, the duration of the smoking period has proved to be 
an independent predictor of $\mathrm{ACD}$, surmounting $\mathrm{AH}$ and $\mathrm{DM}$ effects $^{(14)}$. The presence of risk factors and their severity have an impact on ACD progression. Likewise the control of DV and AH may influence ACD progression. In the clinical trial "Diabetes and Complications", which involved type 1 diabetes, the conventional treatment was compared with intensive treatment by evaluating ultrasonographic data. After six years of study, there was a decrease in the progression of carotid IMT in the group with intensive treatment ${ }^{(29)}$. Most studies about risk factors linked with CVA indicate that high serum levels of cholesterol slightly increase the risk of ischemic CVA, even though some authors claim that dyslipidemia may not constitute a risk factor for it. Notwithstanding, it may be related to the increase of serum cholesterol $^{(1)}$. At Framingham score, considering the isolated punctual measurement, there was no association between cholesterol levels and carotid stenosis (1,189 individuals). However, there was a significant association between carotid stenosis and TC when the measurement was assessed through an eight-year period, which suggests that dyslipidemia may have a delayed effect on ACD in comparison with coronary atherosclerosis. The performance of exact Fisher's test between carotid stenosis levels (NASCET) and HDL-C levels ( $>$ ou $\leq$ $40 \mathrm{mg} / \mathrm{dl}$ ) did not demonstrate a major association. Maki et al. ${ }^{(17)}$ showed that the carotid IMT measurement was inversely associated $(p<0.001)$ when compared with IMT progression. After the adjustment of the initial measurement to IMT standardization, several major predictive factors were substantiated for IMT progression by use of linear regression analysis: glucose $(p=0.044)$, HDL-C, inverse relation, $(p=0.006)$, TG $(p$ $=0.006)$ and ratios TC/HDL-C $(p=0.013)$, TG/HDL-C $(p=$ $0.005)$, and apo B/HDL-C $(p=0.021)$. The following predictors were demonstrated for the posterior IMT: TC $(p=0.028)$, LDL-C $(p=0.035)$, non HDL-C $(p=0.004), \mathrm{TG}(p=0.016)$, apo B $(p=0.005)$, and ratios TC/HDL-C $(p<0.001)$, TG/HDL-C $(p=$ $0.015)$, apo B/apo AI $(p=0,012)$ and apo B/HDL-C $(p=0.004)$. In comparison with previous doppler studies, it was observed that there is the prevalence of atherosclerotic disease in all associated diseases ( $p<0.05$, Fisher), excepting hypothyroidism, in which there was similar prevalence among normal patients and among those with atherosclerotic plaques. Nevertheless, when the relation ACD and IMT was assessed in patients with hypothyroidism, highly significant results were yielded $(p<$ 0.0001; RR $=5.2$; Fisher's test).

The clinical findings with Castelli I and II indexes did not corroborate ACD data, insofar as they are below the alleged risk rates, that is to say Castelli I is lower than 5 for men and lower than 4.4 for women and Castelli II is lower than 3.3 for men and lower than 2.9 for women (Table 1). Gender stratification (Castelli I among patients without ACD) did not demonstrate any difference $(p=0.2169$; unpaired $t$ test). The group with ACD yielded similar result $(\phi=0.1509$; unpaired test with different standard deviation $\mathrm{SD})$. The comparison between the groups with and without ACD for the same index, considering both genders, was not significant ( $p=0.8464$ and 0.5167 ; unpaired $t$ test, respectively).

The comparison between Castelli II indexes did not evince any significance $(p>0.05)$. The results from Castelli I and II between the groups with and without ACD may be explained by the use of hypolipidemic medication and the changes in TC and LDL-C concentrations ${ }^{(24)}$. As to Gazziano index, ratio TG/HDL-C, which estimates the presence of small and dense LDL, our study substantiated evidences lipoprotein particles lower that $25 \mathrm{~nm}$ in both groups with and without $\mathrm{ACD}^{(19,31)}$. There was no major difference in the ratio TG/HDL-C between the groups, though data were almost significant for the male group with and without ACD $(p=0.0596$, unpaired $t$ test).

Concerning data from HDL-C $>40 \mathrm{mg} / \mathrm{dl}$ group and PON1 activity between the groups (HDL-C $>$ and $<\mathrm{d} 40 \mathrm{mg} / \mathrm{dl}$ ), there were no significant associations (Table 2). In accordance with Kabaroglu et al. ${ }^{(11)}$, PON1 activity is not related to HDL-C concentration.

Simvastatin was most common oral hypolipidemic medication administered at 20-40 mg concentration daily, preferably at night. The present study focused on evaluating the relation between serum concentration of lipidic metabolism biomarkers, PON activity and carotid doppler sonography results, correlating them with CAS as a risk marker in the HDL metabolism assessment. According to several studies ${ }^{(24}$ ${ }^{25)}$, simvastatin may have partly influenced HDL cholesterol concentrations, inasmuch as statins, though they promote a considerable reduction of TC and LDL-C, they do not influence HDL in its remodeling ${ }^{(24)}$. There was no participant with isolated low HDL-C levels in use of nicotinic acid, hypolipidemic drug that raises HDL-C levels considerably, although it does not interfere in PON1 activity ${ }^{(25)}$. As patients had already been in use of medication for a considerable period, it was not possible to discontinue the treatment due to ethical reasons.

\section{CONCLUSION}

Although ACD appears according to age progression in both genders, and approximately a decade earlier within the male group, in this sample the female group showed a higher prevalence within the age range 56-65 with RR 1.56 times higher. These results substantiate the special attention required by this group and age range, inasmuch as the lack of estrogenic protection may heighten the risk of ACD and atherosclerosis in other vessels. This is due to the fact that there is no protection against the action of the atherogenic lipidic profile, which contains small and dense LDL particles, herein estimated in both groups with and without ACD in relation to ratio TG/HDL-C. Thus, it may interfere in the HDL antioxidant activity as it directly acts on PON1, though HDL concentrations do not influence PON1 activity. 


\section{RESUMO}

Introdução: Complicações da aterosclerose agregam as principais causas de morte no mundo por problemas cardiovasculares relativos a distúrbio da condição mecânica e fisiológica que promove espessamento e endurecimento nas artérias. Objetivo: Avaliar as concentracõos plasmáticas de biomarcadores do metabolismo lipídico e os resultados de doppler de carótidas, relacionando-os com a doença aterogênica de carótidas. Métodos: Foram acompanhados 66 pacientes, com a média de idade entre 57,5 $\pm 15,5$ anos, (20 a 77), sendo 63\% mulheres. Utilizaram-se biomarcadores séricos e imagens (doppler) para avaliar a associação com a doença aterogênica carotídea (DCA). Resultados e discussão: A DCA foi mais prevalente no gênero feminino (33\% vs. 15\%) entre as idades de 56-65 anos, risco relativo (RR) 1,56 nas mulheres (p <0,002; Fisher, Katz). Em relação ao colesterol da lipoproteína de alta densidade (HDL-C) e à classificação da estenose de carótidas, North American Symptomatic Carotid Endarterectomy Trial (NASCET), observamos que 76\% dos individuos apresentavam HDL-C na faixa protetora, sendo 31 grau I (normal); 81\% possuíam lipoproteína de alta densidade (HDL) sérica $>40 \mathrm{mg} /$ dl em comparação com 19\% que tinham concentração de HDL-C $\geq 40 \mathrm{mg} / \mathrm{dl}$. A prevalência de HDL-C > $40 \mathrm{mg} /$ dl nos graus II, III e IV foi significativa. Não houve diferença de HDL-C entre os grupos ( $\mathrm{p}=0,4910$, teste t não pareado). Não foi observada diferença entre as atividades de paraoxonase (PON1) quando estratificada para $H D L-C>e<q u e ~ 40 \mathrm{mg} / \mathrm{dl}$ ( $\mathrm{p}>0,05$ ). Conclusão: 0 gênero feminino teve maior prevalência de DCA entre 56-65 anos, RR 1,56 vezes maior. Esse achado revela a importância de atenção nesse gênero e nessa faixa etária, uma vez que a ausência de proteção hormonal agrava o risco de DCA, podendo influenciar na atividade antioxidante da HDL por atuar diretamente na PON1. A razão triglirecídeos (TG)/HDL-C aponta para risco cardiovascular e deficiências no transporte reverso do colesterol.

Unitermos: aterosclerose; ecocardiografia vascular; paraoxonase; lipoproteínas.

\section{REFERENCES}

1. ARAÚJO, F. et al. Aumento do índice de massa corporal em relação a variáveis. Arq Bras Cardiol, v. 88, n. 6, p. 624-9, 2007.

2. ASAHARA, T. et al. Bone marrow origin of endothelial progenitor cells responsible for postnatal vasculogenesis in physiological and pathological neovascularization. Circ Res, v. 85, p. 221-8, 1999.

3. BARNET, H. J. et al. The North American Symptomatic Carotid Endarterectomy Trial (NASCET) Collaborators. Benefit of carotid endarterectomy in patients with symptomatic moderadte or severe stenosis. N Engl J Med, v. 339, p.1415-25, 1998.

4. BEHRENDT, D. et al. Endothelial function: from vascular biology to clinical applications. American Journal of Cardiology, v. 90, Issue 10, Suppl. 3, p. L40-L48, 2002.

5. Beneficial effect of carotid endarterectomy in symptomatic patients with highgrade carotid stenosis. North American Symptomatic Carotid Endarterectomy Trial (NASCET) Collaborators. $N$ Engl J Med, v. 325, n. 7, p. 445-53, 1991.

6. CARvalHo, A. C. A. et al. Desenvolvimento de placas de ateroma em pacientes diabéticos e hipertensos. $R$ Ci Méd Biol, v. 9, Suppl.1, p. 73-7, 2010.

7. CHEQUER, G. et al. Espessamento médio-intimal da carótida e função endotelial na doença arterial coronariana.Arq Bras Cardiol, v. 87, n. 2, 2006.

8. CRAVEN, T. E. et al. Evaluation of the associations between carotid artery atherosclerosis and coronary artery stenosis. A case-control study. Circulation, v. 82, p. 1230-42, 1990.

9. FRIEDEWALD, W. T. et al. Estimation of the concentration of lowdensity lipoprotein cholesterol in plasma, without use of the preparative ultracentrifuge. Clinical Chemistry, v. 18, p. 499-502, 1972.

10. JORGE, P. A. R. Endotélio, lípides e aterosclerose. Arq Bras Cardiol, v. 68 , n. 2, p. 129-34, 1997.
11. KABAROGLU, C. et al. Association between serum paraoxonase activity and oxidative stress in acute coronary syndromes. Acta Cardiol, v. 59, n. 6 , p. 606-11, 2004.

12. KABŁAK-ZIEMBICKA, A. et al. Relationship between carotid intima-media thickness, cytokines, atherosclerosis extent and a two-year cardiovascular risk in patients with arteriosclerosis. Kardiologia Polska, v. 69, n. 10, p. 1024-31, 2011.

13. KAPRAL, M. K. et al. Gender differences in carotid imaging and revascularization following stroke. Neurology, v. 73, n. 23, p. 1969-74, 2009.

14. LEMOS, P. A. et al. Unrestricted utilization of sirolimus-eluting stents compared with conventional bare stent implantation in the real world: the Rampamycin-Eluting Stent Evalueted At Rotterdam Cardiology Hosita (RESEARCH) registry. Circulation, v. 109, p. 190-5, 2004.

15. LIMA, E. S. et al. Estrutura, metabolismo e funções fisiológicas da lipoproteína de alta densidade. J Bras Patol Med Lab, v. 42, n. 3, p. 169-78, 2006 .

16. MACKNESS, B. et al. Serum paraoxonase (PON1) 55 and 192 polymorphism and paraoxonase activity and concentration in non-insulin dependent diabetes mellitus. Atherosclerosis, v. 139, n. 2, p. 341-9, 1998.

17. MAKI, K. C. et al. Indicators of the atherogenic lipoprotein phenotype measured with density gradient ultracentrifugation predict changes in carotid intima-media thickness in men and women. Vascular Health and Risk Management, v. 8, p. 31-8, 2012.

18. MAKI, K. C. et al. Predictors of anterior and posterior wall carotid intima media thickness progression in men and women at moderate risk of coronary heart disease.J Clin Lipidol, v. 5, n. 3, p.141-51, 2011.

19. MARUYAMA, C. et al. Assessment of LDL particle size by triglyceride/ HDL-cholesterol ratio in non-diabetic, healthy subjects without prominent hyperlipidemia.J Atheroscler Thromb, v. 10, p. 186-91, 2003.

20. MATTHEWS, K. A. et al. Menopause and risk factors for coronary artery disease. N Engl J Med, v. 321, p. 641-5, 1989. 
21. MENDOZA-SASSI, R. et al. Utilización de los servicios de salud: una revisión sistemática sobre los factores relacionados. Cad Saúde Pública, v. 17, n. 4, p. 819-32, 2001.

22. PARK, S. J. et al. A paclixatel-eluting stent for the prevention of coronary restenosis. $N$ Engl J Med, v. 348, p. 1537-45, 2002.

23. PAULETTO, P. et al. Smooth-muscle-cell proliferation and differentiation in neointima formation and vascular restenosis. Clin Sci (Lond), v. 87, p. 467-79, 1994.

24. PESARO, A. E. et al. Pleiotropic effects of ezetimibe/simvastatin vs. high dose simvastatin. Int J Cardiol, v. 13292, p. 1-5, 2011.

25. PUK, C. G. et al. Transfer cholesterol and other lipids from a lipid nanoemulsion to high-density lipoprotein in heart transplant patients. J Heart Lung Transplant, v. 28, n. 10, p. 1075-80, 2009.

26. RADER, D. J. High-density lipoprotein metabolism as a therapeutic target for atherosclerosis. Cardiology Rounds, v. 6, p. 10, 2002.

27. RANDOUX, B. et al. Carotid artery stenosis: prospective comparison of CT, threedimensional gadolinium-enhanced $\mathrm{MR}$, and conventional angiography. Radiology, v. 220, p. 179-85, 2001.

28. SANTOS, M. G.; PEGORARO, M.; SANDRINI, F.; MACUCO, E. C. Fatores de risco no desenvolvimento da aterosclerose na infância e adolescência. Arq Bras Cardiol, v. 90, n. 4, p. 301-8, 2008.

29. SERRUYS, P. W. et al. Arterial revascularization therapies study. II Sirolimus-eluting stents for the treatment of patients with multivessel de novo (?) coronary artery lesions. Euro Intervention, v. 1, p.147-56, 2005.

30. STAESSEN, J.A. et al. Menopause and the characteristics of the large arteries in a population study.J Hum Hypertens, v. 15, p. 511-8, 2001

31. VIEIRA, E. A. et al. Razão triglicérides/HDL-C e proteína C reativa de alta sensibilidade na avaliação do risco cardiovascular. J Bras Patol Med Lab, v. 47 n. 2 p. 113-8, 2011.

32. WILDMAN, R. P. et al. A dietary and exercise intervention slows menopause-associated progression of subclinical atherosclerosis as measured by intima-media thickness of the carotid arteries. J Am Coll Cardiol, v. 44, n. 3, p. $579-85,2004$.

\section{MAIL ADDRESS}

\section{Ricardo David Couto}

Universidade Federal da Bahia; Rua Barão de Geremoabo, s/n; Faculdade de Farmácia - Campus Universitário de Ondina; Ondina - Salvador-BA, Brazil; CEP: 41170-290; Phone.: (71) 3283-6952/6974/8095/8093; e-mail: rdc@ufba.br 